\title{
What Drives Innovation in Communication Satellites? Lessons from History
}

\author{
Zoe Szajnfarber, ${ }^{*}$ Margaret V. Stringfellow ${ }^{\dagger}$ and Annalisa L. Weigel ${ }^{\star}$ \\ Massachusetts Institute of Technology, Cambridge, MA, 02139
}

\begin{abstract}
This paper captures the first detailed attempt to quantitatively analyze innovation in the space sector. Building on a communication satellite innovation metric and a spacecraft innovation framework developed as part of an ongoing project, this paper presents a preliminary model of communication satellite innovation. In addition to innovation being a function of the rate of performance normalized by price, innovation was found to be strongly influenced by characteristics of the customer-contractor contractual relationship. Specifically, DoD contracts tend to result in a lower level of innovation on average as compared to other customers and particular customer-contractor pairs perform differently and exhibit a second order relationship in time.
\end{abstract}

\section{Nomenclature}

$\alpha, \beta, \gamma, \quad=$ regression coefficients for technical, generational and contractual components respectively

$C_{i} \quad=$ contractual parameter

$t \quad=$ time

$g_{i} \quad=$ generational parameter

$I \mathrm{cu}_{i} \mathrm{con}_{j}=$ customer contractor interaction effect

$I M \quad=$ innovation metric

Mcont $_{\mathrm{i}}=$ contractor main effect

Mcust $_{\mathrm{i}}=$ customer main effect

\section{Introduction}

$\mathrm{T}$ HE engineering systems required for space and defense applications are typically sophisticated, technologically complex, and expensive, with long development times and short production runs. They are designed to the specifications of a particular customer, whose needs often exceed the current technological state-of-the-art. However, despite this implicit requirement to innovate, it is debatable whether traditional government acquisition practices are achieving this goal. While impressive technological feats are unquestionably being achieved, the question remains whether the exorbitant price tags that have become commonplace are truly required to achieve the rapid advances in system functionality. Or, whether there exist more efficient approaches to encouraging innovation in the monopsony-oligopoly market structure characteristic of government acquisition.

Part of the problem is a poor understanding of how characteristics of the space sector (i.e., monopsony-oligopoly market structure and extremely complex robust products) impact the way in which innovation can and should be encouraged. This can lead to inappropriate choices of innovation strategies and, ultimately, to an environment that does not foster innovation successfully. Since effective change is necessarily preceded by an increased understanding of what is currently wrong, this research work aims to fill that gap by identifying and explaining patterns of spacecraft innovation through an analysis of the sector's history.

\footnotetext{
${ }^{*}$ Graduate Research Assistant, Department of Aeronautics and Astronautics and Engineering Systems Division, 77 Massachusetts Ave. Building 17-110, zszajnfa@mit.edu. Student Member AIAA.

${ }^{\dagger}$ Graduate Research Assistant, Department of Aeronautics and Astronautics. Student Member AIAA.

* Assistant Professor of Aeronautics and Astronautics and Engineering Systems. Associate Fellow AIAA. 


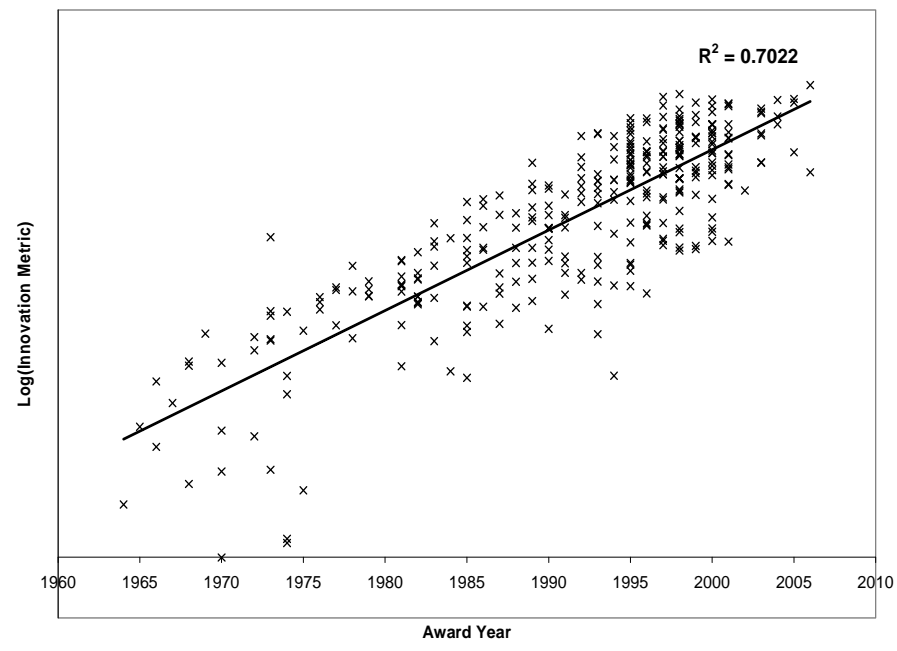

Figure 1. Trends in Communication Satellite Innovation

In order to gain insights from historical data effectively, one needs two pieces: first, a suitable parameter to "track" and second, a testable hypothesis around which to structure the investigation. Previous work by the authors ${ }^{1}$ addressed the first piece, developing an innovation scoring metric for communication satellites, using a first-principles engineering approach. Building on ideas from the cost estimation and trade-space exploration literature, a technically-oriented innovation "score" was developed which sought to capture improvements in capability (normalized by cost) as experienced by the user. The final selection of innovation $=\mathrm{d} / \mathrm{dt}($ power*life $/$ cost $)$ allowed 350 programs spanning 50 years of history (as recorded in the Communication Satellite Database ${ }^{2}$ (CSD)) to be compared directly. Examined as a whole, the data revealed a strong indication $\left(\mathrm{R}^{2}=0.7\right)$ of exponential growth in the sector's "capability baseline" overtime, as shown in Fig. 1. However, extreme variations of individual program performance around the industry mean are also apparent, suggesting that other important factors are at play. Since the goal is to improve the spacecraft innovation process, based on an increased understanding of what drives innovation in the industry, it is this variation that must be explained.

Thus, this paper reports on the next step in this research effort, seeking to explain the variation in the residuals of the regression shown in Fig. 1. There are two main phases to this work. First, the complementary strategies of data mining and theory guided exploration are employed to find statistically significant trends in the data. Second, the historical contexts of the "patterns" are probed in an effort to match theory to practice.

\section{Identifying Key Explanatory Parameters}

The metric defined in ref. 1 frames innovation in its technical and economic context, measuring how the cost of achieving a particular level of functionality changes over time. However, even if the innovation metric could perfectly express the capability level of a particular satellite, one would not expect all the data points to fall exactly on the exponential trend line. Firstly, while in the aggregate, innovation may appear as a steady, incremental, exponential growth there is strong evidence that technological change proceeds as a combination of incremental steps and radical leaps (see for example ref. 3, 4). This leads to the familiar patterns of sequential s-curves. Secondly, real markets do not operate at perfect economic equilibrium, meaning that characteristics of the particular product development and transaction can influence its level of innovation relative to the expected. It is believed that these two types of variations, referred to as generational and contractual factors respectively, account for the variation observed in Fig 1.

In addition to the power, life and cost parameters used in the innovation metric described above, the CSD contains multiple other parameters which allow the relative impacts of generational and contractual factors to be investigated numerically. This section describes how data mining techniques were used initially and later refined with an exploration guided by theory to refine the baseline model of innovation presented in ref 1 . In other words, the goal is to explain more of the variation observed in Fig 1.

\section{A. Method 1: Data Mining}

The remaining CSD parameters (i.e., those not used in defining the innovation metric (IM)) were coded as either: time $(\mathrm{t})$, generational $\left(\mathrm{g}_{\mathrm{i}}\right)$ or contractual $\left(\mathrm{C}_{\mathrm{i}}\right)$, and fit to a regression model of the form:

$$
\mathrm{IM}=\alpha_{0}+\alpha_{1} \mathrm{t}+\beta_{1} \mathrm{~g}_{1}+\ldots+\beta_{\mathrm{n}} \mathrm{g}_{\mathrm{n}}+\gamma_{1} \mathrm{C}_{1}+\ldots+\gamma_{\mathrm{n}} \mathrm{C}_{\mathrm{n}}
$$

The parameter coding and regression results are summarized in Table 1. The results indicate that multiple contractual factors are statistically significant, but the single generational parameter is not. Nonetheless, including the significant factors in the regression generates only a relatively minor improvement in the overall fit (from $\mathrm{R}^{2}=$ 0.7 to 0.72 ). 
Table 1. Regression Output, considering all factors

\begin{tabular}{|c|c|c|c|c|c|c|c|}
\hline Variable & Code & Description & Units & Coefficient & Std Err & t-value & p-value \\
\hline Constant & $\mathrm{aO}$ & & & -105.32 & 4.48 & -23.5 & 0 \\
\hline Awdate & $\mathrm{t}$ & Date of contract award & time & 0.054 & 0.0023 & 23.99 & 0 \\
\hline Arch & g1 & $\begin{array}{l}\text { Dummy variable denoting stabilization method } \\
\text { (spin vs 3-axis stabilized) }\end{array}$ & $0 / 1$ & \multicolumn{4}{|c|}{ not statistically significant, $p$-value $>0.05$} \\
\hline Location & $\mathrm{C} 1$ & $\begin{array}{l}\text { Dummy variable used to differentiate between } \\
\text { customers located in the western world (i.e., N. } \\
\text { America and Europe) or the rest of the world }\end{array}$ & 0,1 & 0.1147 & 0.042 & 2.75 & 0.006 \\
\hline Org & $\mathrm{C} 2$ & $\begin{array}{l}\text { Dummy variable used to differentiate between } \\
\text { government and non-government customers }\end{array}$ & 0,1 & -0.139 & 0.0495 & -2.82 & 0.005 \\
\hline Type & C3 & $\begin{array}{l}\text { Dummy variable for "firm fixed" versus "cost- } \\
\text { plus" contracts }\end{array}$ & 0,1 & 0.0632 & 2.261 & 0.0245 & 0.0185 \\
\hline
\end{tabular}

\section{Significance of Contractual Parameters - Limitation of the Coding}

On first pass, it might seem strange that all the contractual parameters are significant but barely improve the regression model. This result is likely a byproduct of the granularity of the coding; namely, categorizing customers as broadly as "all American non-government firms" is not much better than customers in general. This does not mean that no customer category would improve the metric. Thus finer categories will be examined in Method 2: Theory Guided Exploration.

2. Insignificance of the Generational Parameters - Removing the Time Dependence

The insignificance of the generational parameter is surprising, since the phenomenon of sequential "s-curves" is well established (see for example ref 5). However, the communication satellite industry has not experienced major waves of creative destruction as in other industries, in part because of the significant government involvement in the early stages and stable oligopoly of system integrators. As a result, the dominant design ${ }^{6}$ of 3 -axis stabilized, large, geostationary satellites emerged quite quickly and wasn't replaced until the relatively recent emergence of low earth orbit (LEO) constellations. However, limitations of the innovation metric (described in more detail in ref 1) result in a limited ability to value the utility of constellations. Thus, the generational investigation is limited to the change from spin-stabilized to 3-axis stabilized architectures.

Figure 2 illustrates the statistical result of no difference. Although there is clearly a difference between the trend line for spin- and 3-axis-stabilized satellites, satellites in the spin category do not fall outside the expected range of innovation level for the given year. Further, a single exponential fit $\left(\mathrm{R}^{2}=0.694\right)$ is slightly better than the combination of two separate fits for the different generations. While one could argue that this is a case where statistical significance is not a good practical measure, this result does justify exploring the advantages of examining the data as a single generation. 


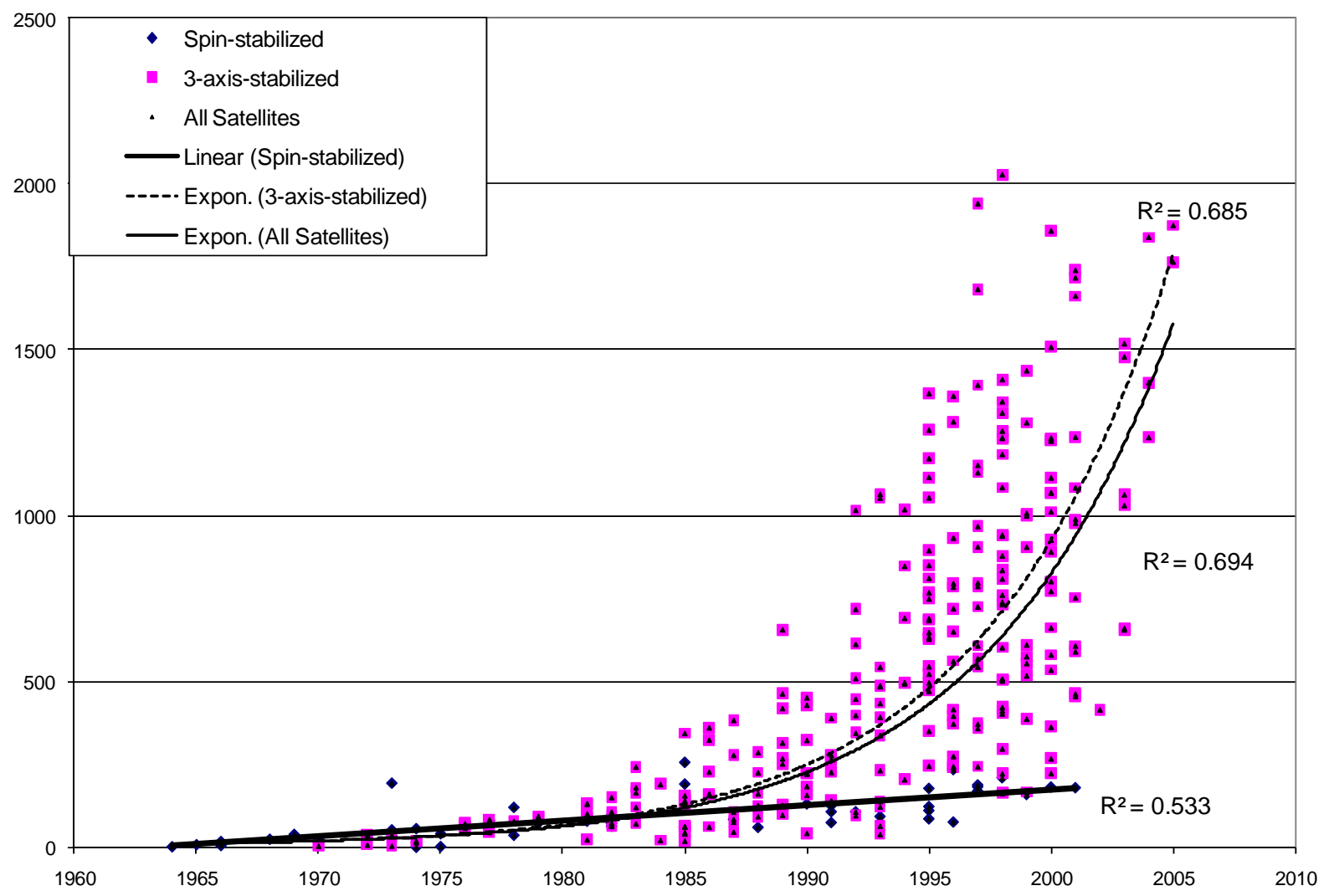

Figure 2. Communication Satellite Generational Differences

The data contained in the communication satellite database is both time-series (spanning 43 years of history) and cross-sectional (including many different types of programs in each year). Innovation occurs over time, but is driven by cross-sectional difference. Although 350 data points may seems like a large number, there are relatively few cross-sectional points in any one year. Thus, since it is relative innovative performance that is of interest from a strategic point of view, the cross-sectional richness of the data-set can be increased by removing the time trend (and thereby standardizing the data). Figure 3 plots innovation level as a difference from the industry mean; it is equivalent to Figure 1 with the time trend-line subtracted out.

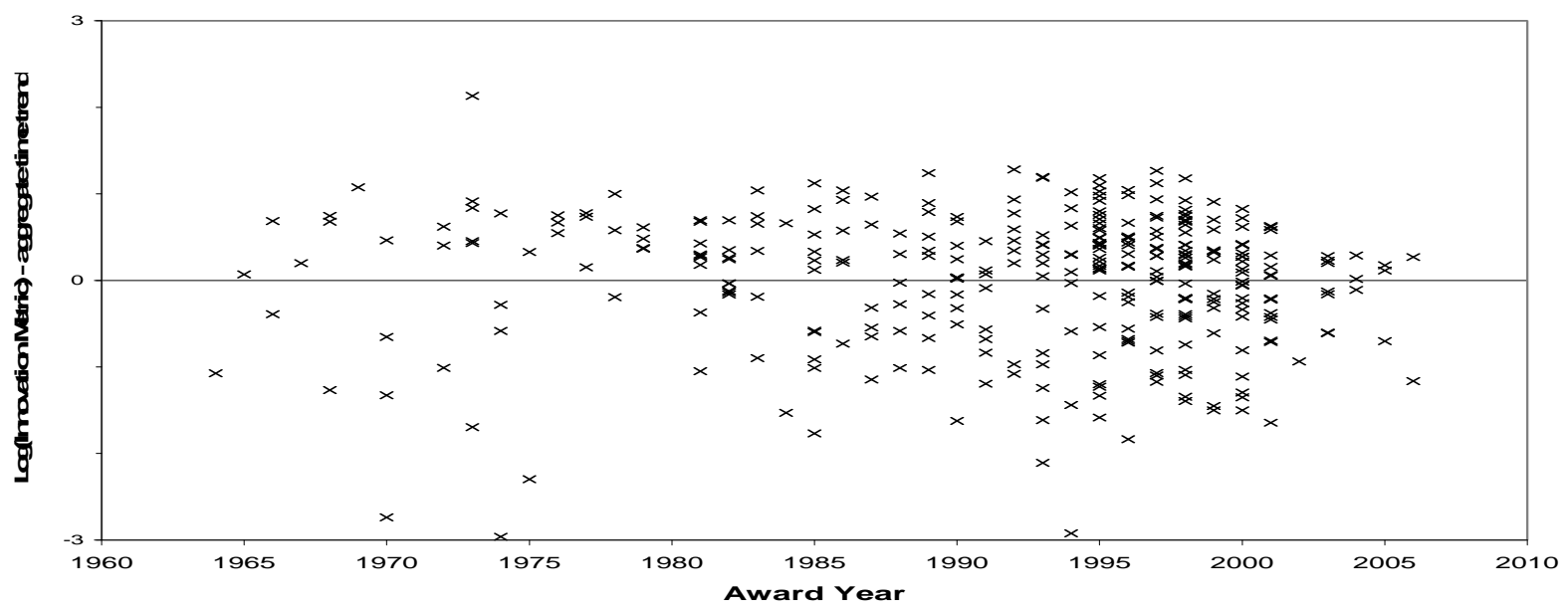

Figure 3 - Deviations from the Industry Innovation Mean

The idea is that the capability baseline of the industry is improving in general (i.e., improvements in power electronics and processor capability should not be attributed directly to any communication satellite project), but 
some types of projects will consistently do better or worse than that mean. And, if the industry baseline is removed, characteristics of an above average project in, for example, 1970 can be compared directly to an equally above average project in 2000 , thus increasing the number of projects that can be compared. The relatively equal spread from the 1960s to the 2010s seen in Fig. 3 demonstrates that this assumption is valid in principle. However, this approach implicitly assumes that a single, consistent increase in the industry capability baseline has occurred over time. As discussed above, this assumption is likely invalid in general for most industries because of generational discontinuities. However, in the context of communication satellites, where the overall architecture has remained relatively constant for most of its history, and there is no statistical difference between the generations, the gains in cross-sectional richness appear to justify the trade.

\section{B. Method 2: Hypothesis Testing}

In the previous section, an effort was made to associate different levels of innovation performance with top-level categories of program type (e.g., American, commercial programs). However, while the categories were found to be statistically significant, in practical terms, the differentiation was too coarse to be useful. In this section, a more detailed, bottom-up approach is taken. Expected patterns are hypothesized based on theory, to be proved or disproved by the data.

\section{Expected Trends: Hypothesis Formulation}

Characteristics of the space market (with its monopsony-oligopoly structure and complex robust products) constrain the ability for transaction dynamics (i.e., the continuous interaction of user needs and seller capabilities) to generate innovation naturally. As a result, where the strategic innovation management literature tends to prescribe ways in which firms and regulators can catalyze, and/or benefit from, dynamics that must exist (see for example, ref. 5 and 6), the goal in the space sector is fundamentally different. Institutional acquisition agencies (e.g., DoD acquisition core, NASA) exist in part to correct for market failures; and thus each of their goals is more to restore a broken dynamic than to strengthen a naturally occurring one. Ref. 7 examines how challenges imposed by the space market structure are corrected for, with varying degrees of success, by the DoD acquisition structure. Ref. 8 performs a similar analysis for the case of the European Space Agency (ESA). In this section, insights gained through that work are leveraged to develop historical "experiments" which can be conducted using the cross-section of program configurations captured in the data in Figure 3.

This paper will not dwell on the underlying theory (see ref. 7 for a more detailed treatment), but a brief background is required to motivate the competing research hypotheses. In the most basic sense, the continuous interaction of user -needs and seller -capabilities are thought to drive innovation. ${ }^{9}$ In a competitive market, both are revealed completely through the mechanism of price. ${ }^{10}$ However, in the monopsony-oligopoly market of space, this information transfer is limited in two ways. Firstly, a monopsony market is discrete and specific since the market only exists when the buyer wants to buy and, as a result, user needs must be specified explicitly since there is no aggregate behavior from which they can be inferred. Further, in the stable oligopoly that exists on the space sector sell-side, there is little incentive for contractors to invest in innovation on their own; they tend to innovate in response to government requests. Based on these constraints, one might expect that innovation in the space sector is dominated by a top-down specified innovation; namely, the customer defines a sufficiently advanced need and contractors are compelled to innovate just to fulfill the contract. In the historical data, this would manifest as a high correlation between level of relative innovation and particular customers (who are smart buyers).

However, this expectation of user-specified innovation presumes that customers are capable of defining the "right" level of advanced specification to drive innovation independently. The task of determining what the best next step vis-à-vis innovation is, for a complex product like a spacecraft, requires the integration of multiple knowledge areas. On the capability side, both a detailed knowledge of the components and their linkages (i.e., architectural innovation ${ }^{11}$ ) is required. However, these areas of expertise are fragmented among system integrators, major subsystem contractors and component suppliers. On the need side, a trade-off must be made between operational desires and budgetary priorities. For example, in the DoD, these areas of expertise are divided between warfighters and congress respectively. As a result, in addition to expecting differences in the ability of customers to represent their needs, there is also a need for contractors to participate in defining the frontier of the possible. Although the nature of this relationship may vary under different circumstances, one would expect the existence of a relationship to facilitate the necessary transfer of information but at the same time limit the incentives to take risks. In the historical data, this would manifest as a high correlation between level of relative innovation and particular customer-contractor pairs.

There is a third competing expectation. Given that contractors possess the detailed technical knowledge on which innovations are built, they are in the best position to initiate innovation. However, as discussed above they have limited incentives to do so because of their stable and powerful market position. That being said, there is still 
an advantage to favorably differentiating oneself from the competition, and prestige to be gained from being involved with successful, highly public projects. In addition, through repeated development efforts, contractors accumulate the complementary assets and tacit expertise which facilitate innovation. ${ }^{12}$ Therefore it would not be unexpected to detect a difference among contractors vis-à-vis innovation. In the historical data, this would manifest as a high correlation between level of relative innovation and particular contractors.

2. Observed Trends: Analysis

Viewed together, the theory suggests that much of the variation in innovation level can be attributed to differences in customers, contractors and the relationship that emerges when they work together. Thus we expect a relationship of the form:

$$
I M-a_{0}-a_{1} t=\sum \operatorname{Mcust}_{i}(t)+\sum \operatorname{Mcont}_{i}(t)+\sum \sum \operatorname{Icu}_{i} \operatorname{con}_{j}(t)
$$

where the terms on the right side of the equation denote the impact of each factor. Hypothetically, a full factorial experiment could be designed to measure each of these factors using an n-factor ANOVA. Particular customers and contractors would randomly be paired to develop satellites over time. You would want every customer to work with every contractor at different (and multiple) points in history. Clearly, such an experiment is not feasible to conduct in practice; however the data captured in Fig. 3 show the results of a 43 year natural experiment, whereby particular customers and contractors have actually paired to develop satellites. Thus, similar analysis can be done on the results of this so-called quasi-experiment.

However, unlike in a designed experiment, the experiment cannot simply be re-run to fill in missing historical data points. Not surprisingly, the history of communication satellite development does not respect the full factorial design (i.e., not every contractor worked with every customer and definitely not multiple times over time). As a result, ANOVA analysis cannot be applied directly. Instead, the main effects (i.e., the effect of each of the customers and contractors independently) are analyzed separately and then the interaction effects (i.e., the additional effect of each customer contractor pairs) for a reduced sample are layered on top. In the analysis that follows, customers and contractors are defined as the buyer and seller as listed on the satellite contract. Where a particular firm has changed names, all instances were grouped as the same customer/contractor (e.g, HAC, HSC, BSC and BSS are all listed as Boeing), but where a company was purchased, broken up and "repackaged," the multiple instantiations are kept separate.

Customer Main Effects: Does the expected high correlation between levels of relative innovation and particular customers (who are smart buyers) exist?

In order to assess whether there is a statistically significant difference between customers, pair-wise t-tests were performed on the difference between each mean (at the $95 \%$ confidence level) ${ }^{\S}$; the Tukey method was used to account for multiple comparisons. Figures 4 and 5 show a summary of the data. ${ }^{* *}$ Figure 4 highlights the data points associated with three customers in particular, demonstrating that while each customer shows considerable variations in innovation levels over time, there is no consistent increasing or decreasing trend in time. Thus the mean

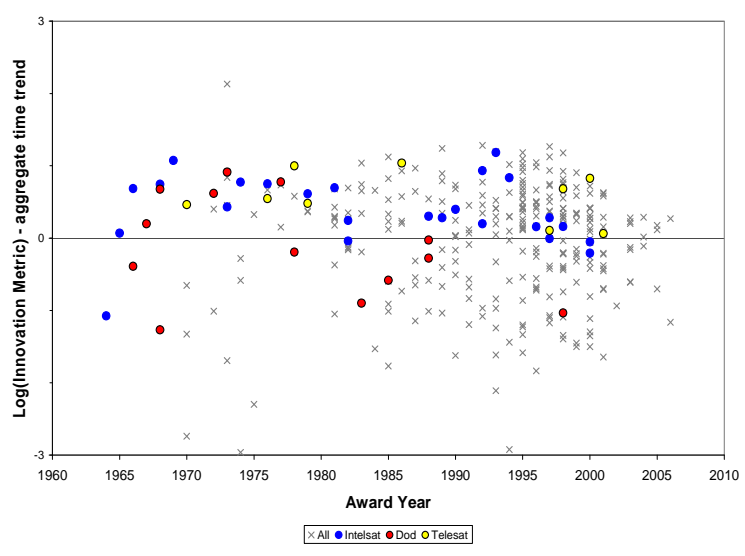

Figure 4 - Customer Differences in Time

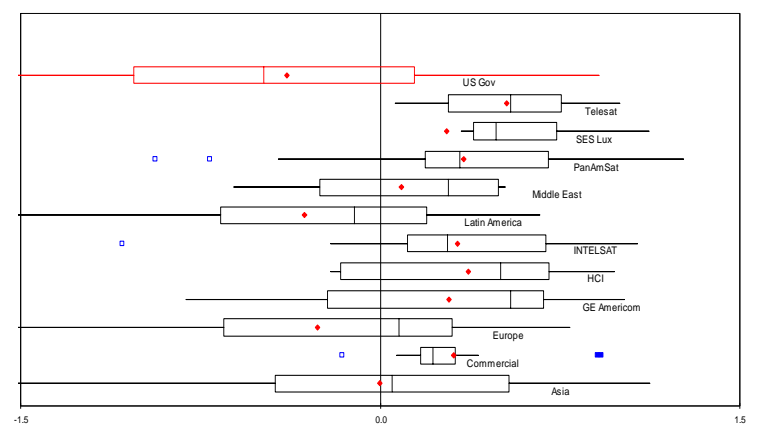

Figure 5 - Box Plot of Customer Comparisons

\footnotetext{
$\S$ Although the assumption of equal variance for the multiple pair-wise t-tests is likely violated, several pair-wise checks (allowing for unequal variances between samples) were run and yielded similar results. Thus it is believed that the equal variance assumption is acceptable in this case.

** Details on the statistical analysis used to generate the results in this paper are available from the authors upon request.
} 
innovation level of each customer can be compared without considering additional time effects. Figure 5 shows a box plot of all the comparisons, which yielded an overall $\mathrm{F}_{(11,184)}$-statistic of 5.8 which corresponds to a p-value of 0.0000 . This provides strong statistical evidence that the satellites contracted by at least one customer (in this case the US DoD as indicated in red in Fig. 5) are systematically different from those contracted by other customers. The other customers are statistically equivalent. In other words, differences in buying ability can impact the project's innovation outcome; however, except for the DoD's poor performance as compared to other satellite customers, the differences are insignificant.

Contractor Main Effect: Does the expected high correlation between level of relative innovation and particular contractors exist?

As above, pair-wise t-tests were performed on the difference between each mean (at the $95 \%$ confidence level).

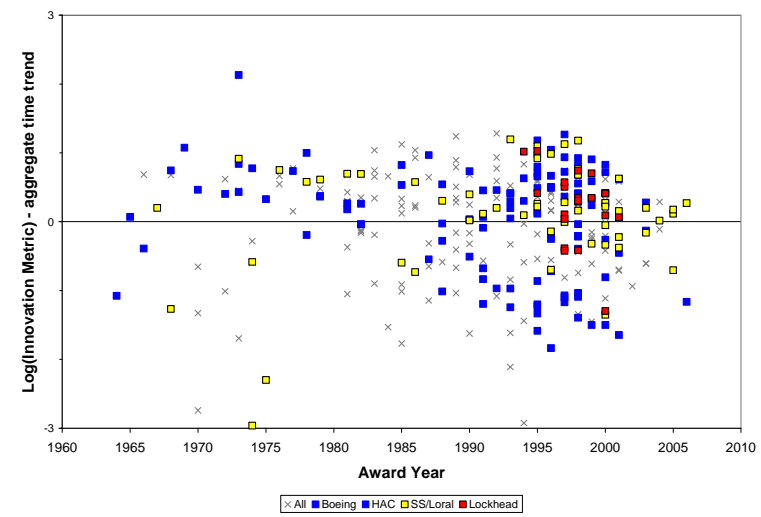

Figure 7. Contractor Differences in Time

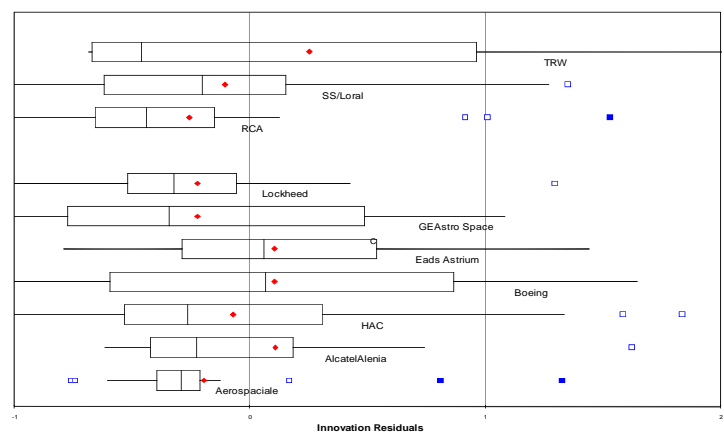

Figure 8. Box Plot of Contractor Comparisons

Again the Tukey method was used to adjust for multiple comparisons. Figures 6 and 7 show a summary of the data. Fig. 6 highlights the data points associated with three contractors in particular, showing that while each contractor shows considerable variations in innovation levels over time, there is no consistent increasing or decreasing trend in time. Thus the mean innovation level of each contractor can be compared without considering additional time effects. Figure 7 shows a box plot of all the comparisons, which yielded an overall $\mathrm{F}_{(9,276)}$-statistic of 1 which corresponds to a p-value of 0.44 . This means that there is no difference, from a statistical point of view, among the innovation outputs of the various contractors. In other words, there is no significant correlation between particular contractors and differences in innovation performance.

Customer-Contractor Interaction Effects: Does the expected high correlation between levels of relative innovation and particular customer-contractor pairs exist?

Since the previous sections revealed that the individual effects of particular customers and contractors are effectively insignificant, their interactions effects can be examined directly. However, there are practical limitations in a historical quasi-experiment which impact on measuring the interaction effects. There are a limited number of customers who have worked with multiple contractors and even fewer pairs of customers and contractors which have alternated working with each other. Thus, for the purposes of this analysis, the data set was reduced to programs involving one of Intelsat, Telesat and US DoD paired with one of Lockheed, Boeing and Space Systems Loral. These firms/agencies were selected purely because they were the only group with enough data points for any meaningful statistical analysis. The data is presented graphically in Figure 9.

As noted earlier, in the customer and contractor cases above, there were no apparent consistent trends in time, making aggregate tests for the difference between means appropriate; however, this is not the case here. In addition, the limited quantity of data in each group makes the prospect of achieving statistically significant differences slim (even if the differences are practically significant). Instead, a regression was performed on each customer set, with dummy variables for each contractor. The following form was assumed:

$$
\left.\operatorname{Icu}_{\mathrm{i}} \operatorname{con}_{\mathrm{j}}(\mathrm{t})\right|_{\mathrm{j}}=\mathrm{m}+\sum \operatorname{Mcont} \mathrm{i}(\mathrm{t})
$$

Even with the limited data, for both the Telesat and Intelsat cases, p-values less than 0.01 were achieved for the overall regression. These differences can be observed qualitatively in Fig. 9. Boeing is the contractor for each of the blue, green and purple data sets yet there was an observable difference in performance. Similarly, on the customer side, while both the green and yellow sets are Telesat acquisitions, there is an obvious difference between the two sets. 
Perhaps the most interesting aspect of Fig. 9 is the apparent higher order trend in time. The nature of this relationship was explored through regression. Least squares fits of the form

$$
\operatorname{Mcont}_{\mathrm{i}}(\mathrm{t})=\mathrm{m}+\gamma_{1} \mathrm{t}+\gamma_{2} \mathrm{t}^{2}
$$

were applied to each customer-contractor pair as shown in Figure 9. While not all significant (as a result of the sparsity of the data), the p-values (shown on the plot) are quite low, providing evidence that a second order relationship exists. In addition, a comparison of Fig. 3 and 9 illustrates dramatically, the extent to which customercontractor interactions explain variations in innovation performance about the industry mean.

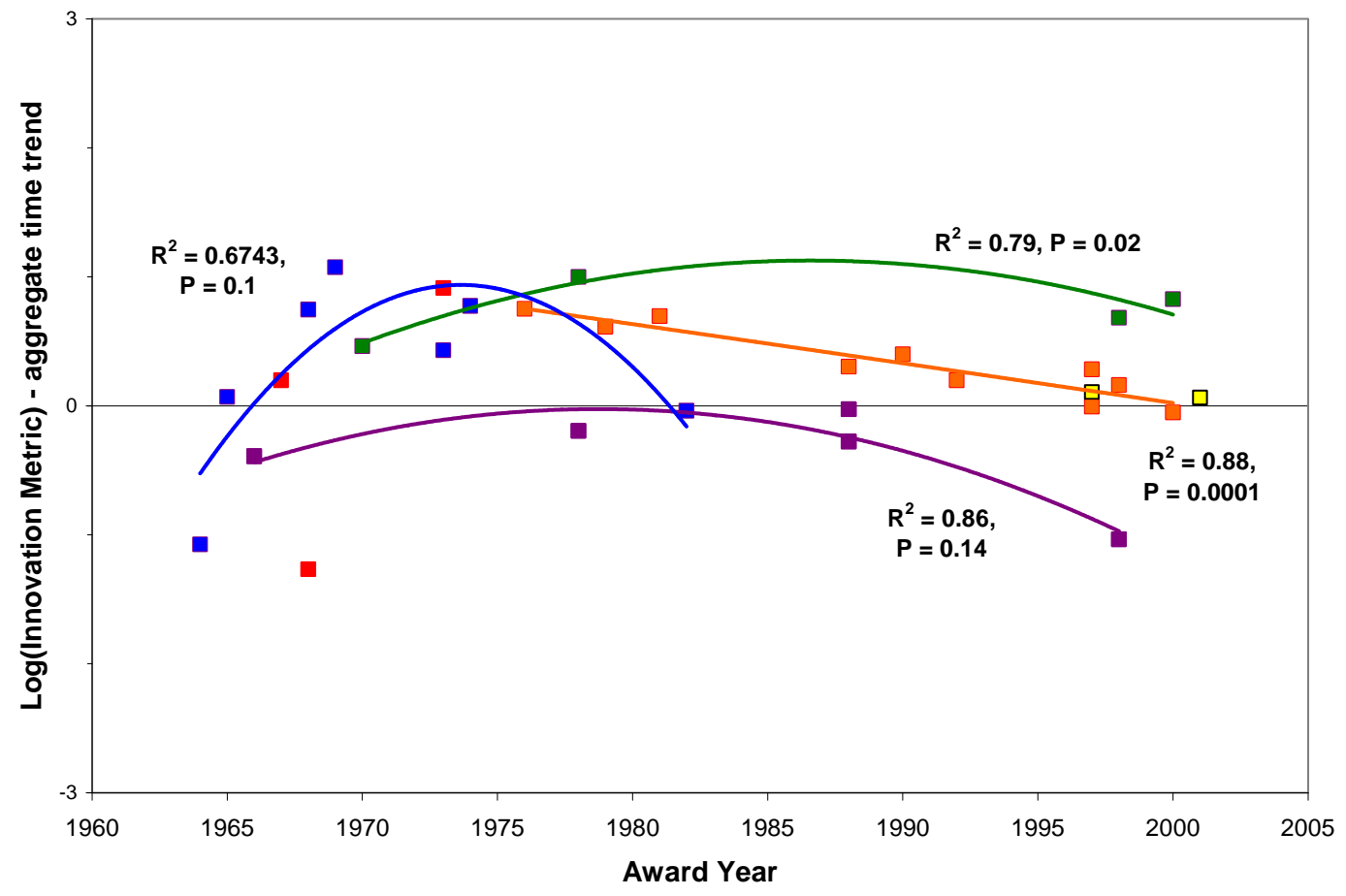

Figure 9. Customer Contractor Interactions

\section{Interpreting the Results}

In the preceding sections, a combination of data mining and statistical hypothesis tests were used to identify parameters key to explaining communication satellite innovation. Recalling that the goal of this work is to improve the innovation model developed in ref. 1 and by extension, work towards developing strategies that foster better innovation in the space sector, this section explains how the above analysis leads to an improved model. It also examines the extent to which these results can be generalized and can be used to inform strategy.

\section{A. Revising the Model}

Ref. 1 argues that innovation can be observed as the rate of change of performance normalized by cost over time. For the case of communication satellites, the following least upper bound estimator was proposed:

$$
\text { Innovation }=\frac{d}{d t}\left[\text { Power } \times \text { Life } / P_{\text {Satellite }}\right]
$$

Using the CSD dataset, the following regression model was estimated:

$$
\operatorname{Ln}(\mathrm{IM})=0.132 \mathrm{t}-257.7 \text { (6) }
$$

However, as discussed above, despite an $\mathrm{R}^{2}$ of 0.7 , significant variation remained in the residuals. This is, in part, because the model only considers technical performance characteristics and cost factors while ignoring generational and contractual parameters. Believing that these later two categories would account for a significant portion of the 
unexplained variation, the above analysis combined data mining and hypothesis testing to identify and measure the importance of these factors.

The above analysis estimated both main and interaction effects for the differences between customers and contractors. Only one main effect was found to be significant; namely, that of the DoD as customer (Mcust $\mathrm{DoD}_{\text {) }}$. The interaction effects associated with several customer-contractor pairs were also found to be significant. Regression coefficients $\left(\mathrm{Icu}_{\mathrm{i}} \mathrm{con}_{\mathrm{j}}\right.$ and $\mathrm{m}_{\mathrm{ij}}$ ) were calculated for combinations of \{Boeing, Lockheed, Loral\}, \{Intelsat, Telesat, $\mathrm{DoD}\}$ as discussed in section II.B.2. When only significant effects are included, the following model results:

$$
\operatorname{Ln}(\mathrm{IM})=0.132 \mathrm{t}-257.7+\text { Mcust }_{\mathrm{DoD}}+\sum \sum\left(\mathrm{m}_{\mathrm{ij}}+\mathrm{Icu}_{\mathrm{i}} \operatorname{con}_{\mathrm{j}} \mathrm{t}^{2}\right)
$$

Equation 7 does not include any generational factors because the analysis revealed that generational differences have not historically been an important differentiator among the innovation performances of communication satellites. That is not to say that they can't be or won't be, especially since architectural parameters have been shown to be more important than business ones in other industries ${ }^{6}$. Rather, that there have not been many major architectural/generational changes and those few have not contributed statistically as explanatory variables in the regression. For this subset of the data, the improvement of the overall fit is substantial (compare Fig. 3 and Eq. 6 with Fig. 9 and Eq. 7) yielding an increased explanation of $\sim 60 \%$.

\section{B. What Have we Learned?}

While there is certainly value to understanding trends in the past, the overriding goal is to improve decisionmaking in the future. The question is thus, how can we use the insights captured in eq. 7 to improve innovation in the space sector? To answer this question fully is beyond the scope of this paper, but as a beginning, this section takes a more detailed look at the implications of the results of the 3 statistical tests performed above. Namely, what does it mean that: 1) the DoD is the only customer that is different from any of the others; 2) no contractor is different from the others; and 3) some customer-contractor pairs are different and exhibit a second order relationship in time?

1. Customer Differences

The customer differences statistical test was premised on the hypothesis that in a monopsony-oligopoly market, an appropriately advanced requirements specification is critical to generating innovation. If this were true, it would follow that "smart buyers," who specified appropriately advanced needs, would generate systematically higher levels of innovation than their less "smart" counterparts. Since the hypothesis that there would be a difference was shown to be false in general, though the $\mathrm{DoD}$ innovation outcomes were found to be different than other customers, what might this imply about a) the importance of requirements specification in general, and b) the DoD acquisition practices in specific?

While the existence of a difference among customers would provide evidence that needs specification is a key determinant of innovation, the lack of difference does not prove that it doesn't. This is because customer differences are not perfect equivalents to differences in how needs are specified. It was hoped that clusters of similar specification strategies would emerge; however, it may be the case that these strategies are more closely linked to project teams than organizations and, therefore, the variations within organizations are too large to observe the differences between them. Since the level of detail required to analyze spacecraft innovation at the project level is not available at present, other avenues will have to be explored.

The fact that the DoD acquisitions yielded innovation levels that were systematically lower than the industry mean is, at least in part, a function of the limitations of the metric. As discussed in ref. 1, the metric is not sufficiently detailed to capture performance characteristics such as encryption and redundancy, upon which the military places much greater value than do commercial operators. In addition the DoD's "block buy" practices, whereby the price for follow-on satellites are locked into the initial contract, is heavily penalized by the metric.

Despite these caveats, the defense acquisition system has received significant criticism in recent years (see for example ref. 13) raising the question of whether this hypothesis test revealed something more significant than a limitation of the metric. One potential explanation for the DoD's lower ranking on the innovation metric is that the $\mathrm{DoD}$ is paying disproportionately for the cost of industry-wide innovation. Specifically, since DoD acquisitions contracts include new technology development costs, from which the industry at large benefits, depending on the magnitude of this investment, they could conceivably register as below average innovators despite being key drivers of change. The nature of DoD innovation is explored further in ref. 7.

\section{Contractor Differences}

The contractor differences test is premised on the hypothesis that since contractors are in a better position to initiate innovation than customers (because of the contractors' intimate component and architectural knowledge), capability differentials among customers will emerge over time despite having limited incentives to innovate. These capability differentials should then lead to observable differences in innovation performance, from which positive 
attributes could be generalized. Since the hypothesis that there would be a difference was shown to be false, what does this imply about the importance of contractor expertise in generating innovation?

While it may be tempting to conclude that a lack of correlation between contractors and innovation performance suggests there is no differentiation among contractors, such an interpretation fails to appreciate the nature of the metric used. Innovation output, as defined in Eq. 5 and implemented in Fig. 1, measures planned performance normalized by contract price; it does not account for discrepancies between contract and delivery, which, as illustrated in recent history, can be significant (e.g., AEHF, NPOESS, SBIRS-High, GPS II). ${ }^{14}$

When the innovation history is viewed as a whole, this inability of the metric to capture delivery price performance is not a major limitation because lessons learned will be captured through the definition of the next specification; however, when particular projects are associated with particular contractors, the metric's limitation is significant. This is because much of the innovation value added by contractors occurs during development and is therefore not reflected in the contract parameters being measured. Thus, while the negative result of the contractors' differences test reinforces the notion that top-down specification plays a critical role in driving spacecraft innovation, it does not prove that differences in contractor expertise are not important as well. For this question to be tested, a database which reports statistics related to actual delivered performance and cost will be required.

\section{Differences in Customer Contractor Interactions}

The idea behind the customer contractor interactions test is that since the critical task of specifying appropriately advanced needs is the customer's responsibility while the detailed knowledge required to do so is possessed by the contractors, then successful collaboration between customers and contractors will lead to higher levels of innovation. The test would identify successful and less successful pairings which can then be examined in more detail to extrapolate generalizable characteristics. Since the hypothesis that there would be a difference was shown to be true within the limits of data availability, what does this imply about how customer contractor relationships should be structured in order to foster successful innovation over time?

The fact that some customer-contractor relationships work better than others is not in itself surprising or a particularly useful categorization. The more interesting element of the above result is the evidence of a second order time trend that it revealed (see Fig. 9), because it yields insight into the structure of the relationship. This structure can be understood in one of two ways. Either the second order relationship is 1) a general phenomenon which results from the underlying innovation dynamics in the sector, or 2) it is the result of the particular set of historical circumstances and would be unique to each development.

Considering first the innovation theory point of view, a second order trend is consistent with the tension between stability and invention that characterizes the innovator's dilemma. ${ }^{5}$ While long term working relationships tend to breed trust and collaboration ${ }^{8}$ which are conducive to incremental innovation and increased efficiency within the existing paradigm, they also limit new ideas which typically come from entrant firms. ${ }^{5}$ It therefore makes sense that levels of innovation would increase initially, but level off and decrease as the relationship became too stable.

On the other hand, consider, for example, the Intelsat-Boeing relationship (captured by the blue trend line in Fig. 9) which shows the most pronounced instance of higher-order behavior in time. In this case, the second order relationship can be explained equally well by an examination of the history. Initially (1965 - mid 70s), Intelsat was the only provider of commercial communication satellite services and drove innovation in the sector by specifying increasingly advanced satellites from its supplier Hughes Aircraft (which later became Hughes Spacecraft, Boeing Spacecraft and Boeing Space Systems, all referred to as Boeing). For the first five series of satellites (I-V), subsequent satellite requirements were substantially increased in one area at a time (either capacity or coverage requirements) and were achieved with innovation in one or two new technologies. ${ }^{15,16}$

The inflection point in the Intelsat-Boeing curve (in the early to mid 1970s) corresponds to both an internal and external shift. Internal to the relationship, the level of ambition in the requirements specification changed; for the last Intelsat-Boeing satellite, series VI, Intelsat required radically new capabilities in three areas: Capacity, Coverage and Flexibility to be achieved with five new technology developments. ${ }^{15}$ External to the relationship, national satellite service providers began to emerge to meet the growing network needs. ${ }^{17}$ This had the effect of both increasing and diversifying the buy-side of the market, which could explain the regression towards the mean in and of itself. Thus, before general statements can be made about how to structure customer contractor relationships so as to foster successful innovation, a more detailed survey of more customer-contractor relationships is required. The next steps involve examining multiple regression results in their detailed historical contexts, so that underlying innovation strategies can be isolated from other incidental market and technology factors.

\section{Conclusion}

To the authors' knowledge, this work represents the first detailed attempt to quantitatively analyze innovation in 
the space sector. Building on a communication satellite innovation metric developed in ref. 1 and the spacecraft innovation framework captured in ref. 7, this paper presents a preliminary model of communication satellite innovation. In addition to innovation being a function of the rate of performance normalized by price, innovation was found to be strongly influenced by characteristics of the customer-contractor contractual relationship. Specifically, DoD contracts tend to result in a lower level of innovation on average as compared to other customers and particular customer-contractor pairs perform differently and exhibit a second order relationship in time. In both cases, the observed phenomenon can be explained by a combination of innovation theory and historical details. Future work will expand the customer-contractor pair analysis, so that fundamental innovation dynamics can be isolated from particular historical circumstances. Already, this paper has demonstrated the ability of this preliminary model to explain significant portions of the variations in innovation performance of hundreds of historical communication satellite programs. In so doing, it creates a basis for categorizing differences, which is a first critical step in developing a prescriptive model for innovation strategy.

\section{Acknowledgments}

Funding for this work was provided by the Center for Aerospace, Systems, Policy and Architecture Research (CASPAR); Cisco Systems Inc.; and the Natural Science and Engineering Research Council of Canada (NSERC).

\section{References}

${ }^{1}$ Szajnfarber, Z. and Weigel, A.L., "Are Spacecraft Cheaper or More Expensive Now and Why? Spacecraft Innovation Trends," AIAA Space 2007, AIAA, Long Beach California, Vol. 12, No. 22, Sept. 17-20 2007

2 Rusch, R., Communication Satellite Database [electronic resource], Palos Verdes, CA: TelAstra, c2006, URL: http://walter.mit.edu/item/001397544 [accessed starting 5 February 2007].

${ }^{3}$ Anderson, P., Tushman, M. L., "Technological Discontinuities and Dominant Designs: a Cyclical Model of Technological Change" Administrative Science Quarterly, Vol. 35, 1990.

${ }^{4}$ Abernathy, W. J. and Clark, K. B, "Innovation: Mapping the winds of creative destruction" Research Policy, Vol. 22, Issue 2. pp. 102-102, 1993.

${ }^{5}$ Christensen, C. (2003). The Innovator's Dilemma. New York, Harper Collins.

${ }^{6}$ Utterback, J. M. (1994) Mastering the Dynamics of Innovation, Harvard Business Press, Cambridge, MA.

${ }^{7}$ Szajnfarber, Z., Richards, M. G., Weigel, A. L., "Implications of DoD Acquisition Policy for Innovation: The Case of Operationally Responsive Space,” AIAA Space 2008, Sept 9-11 2008, San Diego California.

${ }^{8}$ Szajnfarber, Z. and Weigel, A. L., "Innovation Dynamics of Large Complex Technological Products in a Monopsony Market Structure: The Case of ESA Science Missions," Atlanta Conference on Science Technology and Innovation Policy, 19-20 Oct, 2007, Atlanta, Georgia.

${ }^{9}$ Rothwell, R. and Zegveld, W., Reindustrialization and Technology, Longman, Harlow., 1985. As referenced in Rothwell R., “Towards the Fifth-generation Innovation Process," International Marketing Review Vol. 11, No. 1, 1994, pp 7-31.

${ }^{10}$ Adams, W., and Adams, W.J., (1972) "The Military-Industrial Complex: A Market Structure Analysis," The American Economic Review, Vol. 62, No. 1/2, pp. 279-287.

${ }^{11}$ Henderson, R. and K. Clark (1990). "Architectural Innovation: The Reconfiguration of Existing Product Technologies and the Failure of Established Firms." Administrative Science Quarterly, 35: 9-30.

12 Teece, D. J., "Profiting from technological innovation: Implications for integration, collaboration, licensing and public policy" Research Policy, 1986

${ }^{13} \mathrm{GAO}$ (2007). "Space Acquisitions: Actions Needed to Expand and Sustain Use of Best Practices." U.S. Government Accountability Office. Testimony before the Subcommittee on Strategic Forces, Senate Committee on Armed Services, GAO-07$730 \mathrm{~T}$.

${ }^{14}$ GAO (2007). "Space Acquisitions: Actions Needed to Expand and Sustain Use of Best Practices." U.S. Government Accountability Office. Testimony before the Subcommittee on Strategic Forces, Senate Committee on Armed Services, GAO-07$730 \mathrm{~T}$.

${ }^{15}$ Martin, D. H., Communication Satellites, 1958-1995, Aerospace Corporation, El Segundo, California, 1996.

${ }^{16}$ Whalen, D. J., "Communications Satellites: Making the Global Village Possible" NASA History Office Publications, URL: http://www.hq.nasa.gov/office/pao/History/satcomhistory.html [first accessed October 2006].

${ }^{17}$ Beyond the Ionosphere: Fifty Years of Satellite Communication," The NASA History Series, edited by A. J. Butrica, NASA-SP4217, National Aeronautics and Space Administration, NASA History Office, Washington, D.C., $20546,19947$. 